\title{
SUPPORTING REPORTING IN PROJECT MANAGEMENT
}

\author{
Iwona ZDONEK \\ Silesian University of Technology; iwona.zdonek@ polsl.pl, ORCID: 0000-0002-3377-0904
}

Purpose: The article presents the results of qualitative research related to answering the question: "How can reporting be supported when there is no access to professional BI tools?". Design/methodology/approach: The answer to this question was set in the context of the BI layers proposed by Todd (todd 2017). This approach allowed one to determine, in each layer, operations performed on data that support reporting. The main research method was the participation observation made in the author's involvement in the project management team.

Findings: Supporting reporting in project management when there is no access to professional BI tools needs strong technical competences and great creativity by the project management team in using applications such as spreadsheets or database tools. The most helpful functionalities provided by spreadsheets are text and search functions and the data conversion wizard. The most useful functionality provided by database tools was intelligent calculations made by queries and automatic report design provided by MS Access.

Originality/value: The paper presents an examination of the set of operations and IT tools needed in a business analysis made in project management in a situation where there is no access to professional BI tools.

Keywords: reporting support, business intelligence tools.

Category of the paper: Case study.

\section{Introduction}

Reporting in project management is one of the ways to communicate with project stakeholders. This is also the first step in business analysis. Although reporting and analysis draw upon the same collected data, according to Dykes (Dykes, 2010), reporting and analysis are very different in terms of their purpose, tasks, outputs, delivery and value. Thus, for this reason, they can be used neither interchangeably nor as synonyms. He indicates that "reporting is the process of organising data into informational summaries to monitor how different areas of a business are performing" (Dykes, 2010). In other words, reporting is treated as the process of organising data in documents to monitor business performance. Whereas "analysis is the process of exploring data and reports to extract meaningful insights, which can be used to better 
understand and improve business performance" (Dykes, 2010). Thus, analysis is the process of exploring data to draw valuable conclusions that can be used to better understand a business and improve its efficiency. Comparing these two, we can notice that reporting processes raw data into more easily digestible information sets and lets us answer the question "what happened?". Meanwhile, analysis allows us to answer the question "why did it happen?" The main activities performed during reporting are usually automated. Among them, we can indicate: configuring, organising, formatting and summarising. During the analysis process, we ask business questions and research, interpret, compare, confirm or reject hypotheses. Reports are often just a starting point for further business analysis.

As was mentioned above, reporting processes raw data into more easily digestible information sets, although this requires special tools that help execute all needed operations. These tools are connected with a discipline called Business Intelligence (BI). Business Intelligence (BI) is a term used to describe a broad category of applications, technologies, architectures and processes for gathering, storing, accessing and analysing operational data to provide business users with timely competitive information to enable better insights for operational and strategic decision making (Negash, 2004; Watson, 2009). We can observe a wealth of research about business intelligence technology (Bobriakov, 2018; Abbott, 2014; Green 2010), business intelligence education (e.g. Chiang et al., 2012; Davis, and Woratschek, 2015; Sircar 2009; Wixom et al., 2014), design and development of BI curriculum (e.g. Al-Sakran, 2014; Chiang et al., 2012; Gorman, and Klimberg, 2014; Wilder, and Ozgur, 2015) and teaching cases and learning activities for BI (e.g. Edgington, 2011; Pomykalski, 2014; Presthus, and Bygstad, 2012). Although BI tools are more and more widespread, it is not always possible to use them in a project management team. Therefore, the main purpose of this article is to answer the question: "How can reporting be supported when there is no access to professional BI tools?".

The answer to this question is set in the context of the BI layers proposed by Todd (Todd, 2018). This approach allows one to determe, in each layer, operations performed on data that support reporting.

This study is structured as follows: In the chapter entitled Methodology, the methods used in the research are explained. In the chapter Results, the outcomes of the research are then presented. Finally, in the chapter Discussion and Conclusion, the results are discussed. 


\section{Methodology}

Because the objective of this paper is to establish how to support reporting when there is no access to professional BI tools, a case study was conducted. In 2018 and 2019, the author of the article participated in a project whose main goal was a modernisation of education at university. The author's participation was related to taking part in the work of the management team of this project. One of the tasks that the project team had to do was the creation of different kinds of reports. All of them had a financial context and were required by external stakeholders. The reports were based on data coming from internal accounting systems and documents collected by the project team. They covered a period of fifteen months: from October 2018 to December 2019. Some reports were made by grouping and summarising data to set them to the report template and subsequently to the IT system delivered by the external stakeholder. The final version of the reports imported to that system contained items grouped and summarised by different dimensions. Among them, there were: number of project tasks, number of documents, account number, date of the document, date of payment, name of the cost, category of the cost and so on. The other types of reports were not prepared for importing into the IT system, but for control by the external stakeholder.

Following Todd (Todd, 2018), five layers in BI were established (data management, intelligent calculations, delivery mode, consumption device, business enablement). Each of these was investigated in terms of operations performed by a business analyst and in terms of IT tools used during these operations.

\section{Table 1.}

The five BI layers proposed by Todd

\begin{tabular}{|c|c|}
\hline Layer & Skills \\
\hline Data management & $\begin{array}{l}\text { Abilities associated with data wrangling tools: } \\
\text { - } \quad \text { how to join disparate data sources, } \\
\text { - } \quad \text { how to clean data (remove data errors and inconsistencies), } \\
\text { - } \quad \text { how to organise data better for analysis, } \\
\text { - } \quad \text { how to wrangle structured and unstructured data, } \\
\text { - } \quad \text { how to blend structured data with the unstructured sources, } \\
\text { - } \quad \text { being aware of best practices in data wrangling. }\end{array}$ \\
\hline $\begin{array}{l}\text { Intelligent } \\
\text { calculations }\end{array}$ & $\begin{array}{l}\text { Skills related to analytical functions used in BI tools to answer business questions: } \\
\text { - } \quad \text { how to use maths and statistics functions to create calculations, } \\
\text { - } \quad \text { being able to apply the statistic or math functions to answer business questions, } \\
\text { - } \quad \text { how to create, design and administer machine learning applications. }\end{array}$ \\
\hline Delivery mode & $\begin{array}{l}\text { Abilities related to data visualisation tools: } \\
\text { - being able to recognise which chart fits data best, } \\
\text { - } \quad \text { how to display charts best, } \\
\text { - } \quad \text { how not to overwhelm users by visualisation, } \\
\text { - } \quad \text { how to do data storytelling, } \\
\text { - be aware of human factors that influence the perception of visualisation, } \\
\text { - } \quad \text { being aware of best practices in data visualisation. }\end{array}$ \\
\hline Consumption device & $\begin{array}{l}\text { Skills associated with adjustment visualisations to tools used by end-user to consume } \\
\text { visualisations. }\end{array}$ \\
\hline Business enablement & Skills related to the area of training, data quality and metadata. \\
\hline
\end{tabular}




\section{Results}

The most common objects on reports are dimensions and metrics. Dimensions represent business concepts, such as tasks in a project, employee, month and so on. In the terminology of statistics, they are called categorical variables. Putting dimensions on the report provides a context for the data calculations (metrics) that are usually the core of any business reporting. Dimensions serve as labels for metrics values. Metrics represent a business measure or key performance indicator, such as revenue, cost, employee headcount and so on. Metrics are the calculations performed on data stored in a database. In statistics, they are called numerical variables.

When looking at the data management layer, the investigation revealed the presence of the following operations: the support for files that allow the exchange of data between applications, data sorting and filtering, creation of new dimensions based on text functions and assigning dimensions based on search functions. Primarily, it was necessary to join data containing a dictionary description of financial project categories. Secondly, new dimensions had to be created. To meet both requirements, operations using text functions (e.g. LEFT, RIGHT, REPLACE), search functions (e.g. SEARCH, VLOOKUP) and specific condition testing functions (e.g. IF, IFERROR) were applied. The most useful application in this layer were spreadsheets, especially MS Excel.

\begin{tabular}{|l}
\hline Lista płac \\
\hline$=$ LEWY(AA2;ZNAJDŹ(" ";AA2)-1) \\
\hline$=$ LEWY(AA3;ZNAJDŹ(" ";AA3)-1) \\
\hline =LEWY(AA4;ZNAJDŹ(" ";AA4)-1) \\
\hline$=$ LEWY(AA5;ZNAJDŹ(" ";AA5)-1) \\
\hline$=$ =EWY(AA6;ZNAJDŹ(" ";AA6)-1) \\
\hline
\end{tabular}

\begin{tabular}{|l|}
\hline Nazwa kategorii projektowej \\
\hline =WYSZUKAJ.PIONOWO(S2;'Słownik kategorii'!\$A:\$B;2;0) \\
\hline =WYSZUKAJ.PIONOWO(S3;'Słownik kategorii'!\$A:\$B;2;0) \\
\hline =WYSZUKAJ.PIONOWO(S4;'Słownik kategorii'!\$A:\$B;2;0) \\
\hline =WYSZUKAJ.PIONOWO(S5;'Słownik kategorii'!\$A:\$B;2;0) \\
\hline =WYSZUKAJ.PIONOWO(S6;'Słownik kategorii'!\$A:\$B;2;0) \\
\hline
\end{tabular}

Figure 1. Example of new dimensions creation by using text or search functions. Source: own implementation.

When it comes to the intelligent calculation layer, the investigation revealed the presence of the following operations: queries design and creation of calculations (metrics) based on the summarising function. The most valuable IT tools were database applications (MS Access), especially in the area of extracting information using queries. The most useful types of queries were those that allowed one to show aggregations for different groups of dimensions. 


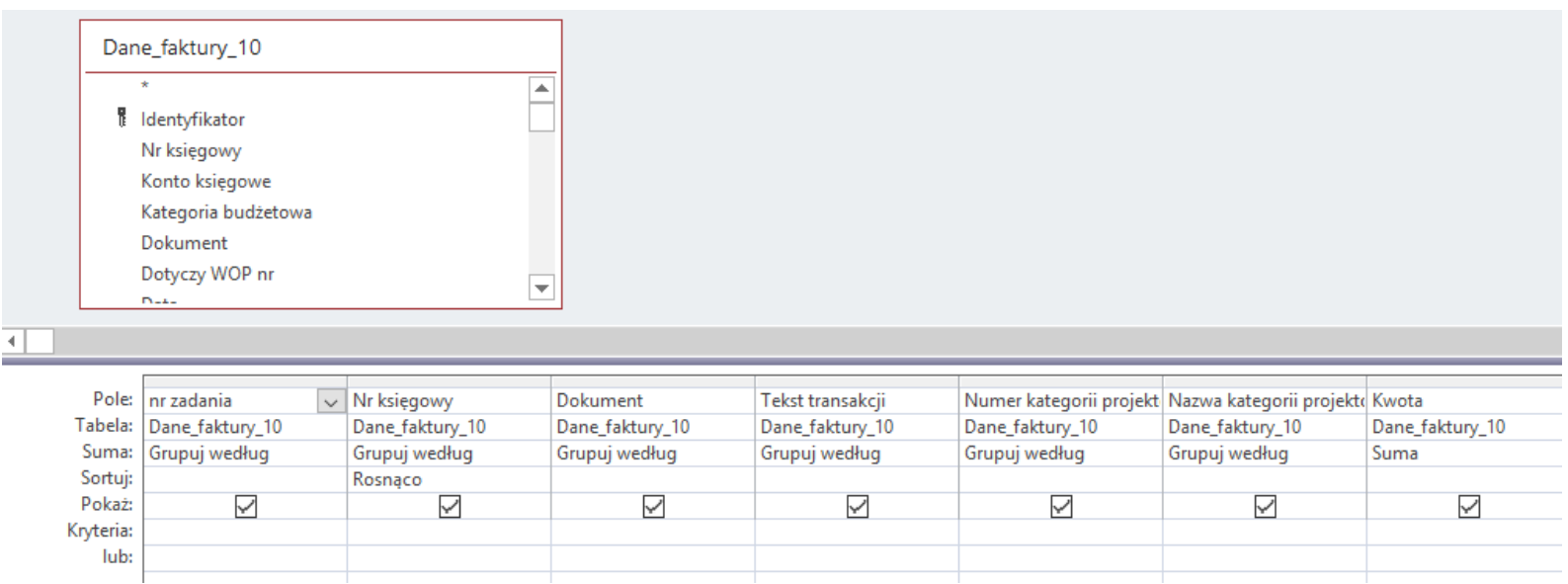

Figure 2. Example of a query design allowing the data aggregation. Source: own implementation.

When looking at the delivery mode layer, the investigation revealed the presence of operations related to designing reports. Thus, reports were created based on dimensions and metrics produced in data management and intelligent calculation layers. To account for the fact that the stakeholder delivered the template of the report, the initial version of the report (made in MS Access) was exported to a template and enriched with additional information. The creation and use of macros turned out to greatly facilitate the work. The main form of data visualisation in this template was grids made by using the spreadsheet.

\begin{tabular}{|c|c|c|c|c|c|c|c|c|c|}
\hline \multicolumn{10}{|c|}{ ZESTAWIENIE DOKUMENTÓW POTWIERDZAJACYCH PONIESIONE WYDATKI } \\
\hline Numer zadania & $\begin{array}{c}\text { Numer } \\
\text { purtnera }\end{array}$ & $\begin{array}{c}\mathrm{Nr} \\
\text { dokumentu }\end{array}$ & $\begin{array}{c}\text { Nr księgowy } \\
\text { lub } \\
\text { ewidencyjny }\end{array}$ & $\begin{array}{c}\text { Rodzaj } \\
\text { identyfikatora }\end{array}$ & $\begin{array}{c}\text { Data } \\
\text { wystawienia } \\
\text { dokumentu }\end{array}$ & Data zaplaty & $\begin{array}{c}\text { Data } \\
\text { zapłaty od z }\end{array}$ & $\begin{array}{c}\text { Data } \\
\text { zapłaty do }\end{array}$ & Nazwa towaru lub usługi \\
\hline \multirow[t]{3}{*}{12} & & $1 \mathrm{PL}$ U UC/026 & WBFP_H/201 & NIP & 04.10 .2019 & \multicolumn{4}{|c|}{ 07.10.2019 PERT ZA OKRES 07.06.2019 DO 28.06.2019; NETTO;ZUS;US; LICZBA GODZ. 3C } \\
\hline & & & & & & 14.11.2019 & & & \\
\hline & & & & & & 19.11.2019 & & & \\
\hline \multirow[t]{3}{*}{1} & & 1 LP/013/151 & WWOFD_H/201 & NIP & 30.09 .2019 & \multicolumn{4}{|c|}{ 01.10.2019Y DO WYNAGRODZENIA ZA OKRES 01.01.2019 DO 28.02.2019; NETTO;ZUS;Us } \\
\hline & & & & & & 14.11.2019 & & & \\
\hline & & & & & & 19.11.2019 & & & \\
\hline \multirow[t]{3}{*}{12} & & $1 \mathrm{LP} / 013 / 151$ & WOFD_H/201 & NIP & 30.09 .2019 & \multicolumn{4}{|c|}{ 01.10.2019Y DO WYNAGRODZENIA ZA OKRES 01.07.2019 DO 31.07.2019; NETTO;ZUS;US } \\
\hline & & & & & & 14.11.2019 & & & \\
\hline & & & & & & 19.11.2019 & & & \\
\hline \multirow[t]{3}{*}{28} & & $1 \mathrm{LP} / 013 / 151$ & WOFD_H/201 & NIP & 30.09 .2019 & \multicolumn{4}{|c|}{ 01.10.2019Y DO WYNAGRODZENIA ZA OKRES 01.09.2019 DO 30.09.2019; NETTO;ZUS;US } \\
\hline & & & & & & 14.11.2019 & & & \\
\hline & & & & & & 19.11.2019 & & & \\
\hline \multirow[t]{2}{*}{12} & & 1 LP/019/151 & WOFD_H/201 & INIP & 30.09 .2019 & \multicolumn{4}{|c|}{ 01.10.2019Y DO WYNAGRODZENIA ZA OKRES 01.02.2019 DO 31.05.2019; NETTO;ZUS;US } \\
\hline & & & & & & 14.11.2019 & & & \\
\hline
\end{tabular}

Figure 3. Part of the report adapted to the template in MS Excel. Source: own implementation.

The possibility of report design, available in MS Access, provided an important functionality and accelerated additional report creation. They were prepared for control processes made by the external stakeholder. 


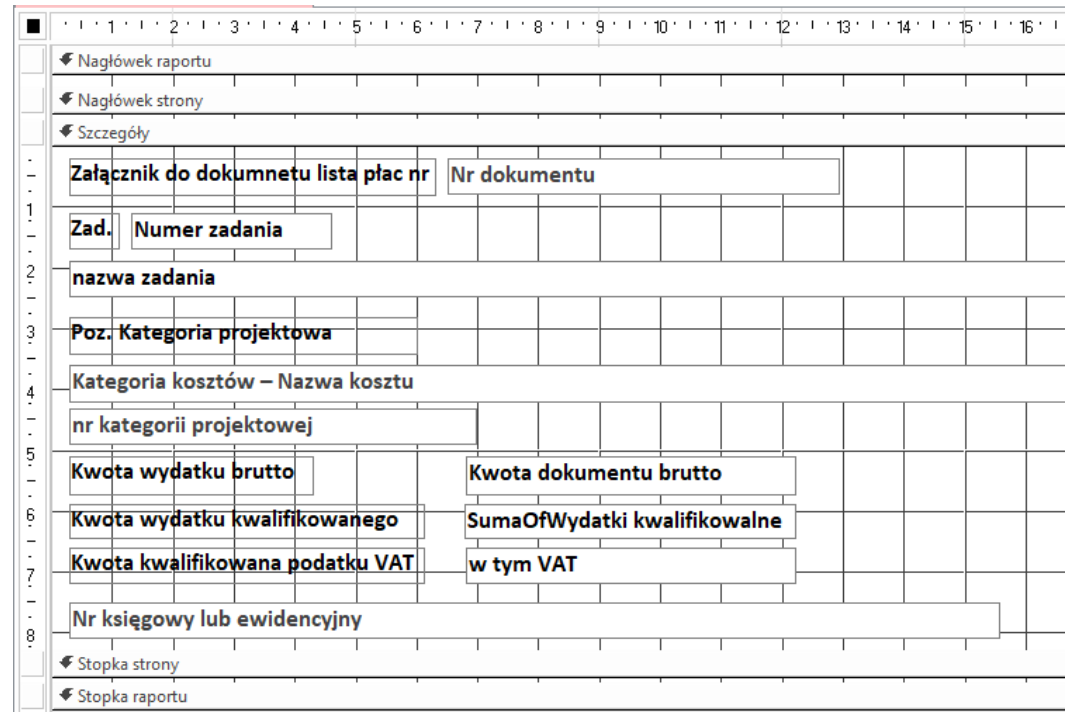

Figure 4. Part of the report design made in MS Access. Source: own implementation.

It is worth noticing that the way of report creation in MS Access is very similar to the way of document creation in the professional BI tool. Both tools used the dimensions and the metrics to create the report in a special view called "design view" that allowed the data and its format to be treated separately.

\begin{tabular}{|c|c|c|c|c|}
\hline \multicolumn{5}{|l|}{ - Page Header } \\
\hline Transactional Sales Report & Sales & Profit & Margin & Units Sold \\
\hline \multicolumn{5}{|l|}{ Document Header } \\
\hline \multicolumn{5}{|l|}{ 曰Customer Header } \\
\hline \{Customer\} & SReves & TProfit & IIProfí & frUnit: \\
\hline \multicolumn{5}{|l|}{ 日ategory Header. } \\
\hline \{Category\} & \{Reved & KProfit & SIProff & frUnits \\
\hline \multicolumn{5}{|l|}{ - Subcotegory Header } \\
\hline \{Subcategory\} & \{Revei & SProfit & \{IProfi & frUnit: \\
\hline \multicolumn{5}{|l|}{ GDetal Header } \\
\hline \multicolumn{5}{|l|}{ GDetal } \\
\hline (ItemodesC) & SRevent & \{Profit\} & ¿lProfie & (IUnits: \\
\hline \multicolumn{5}{|l|}{ 日Detal Footer } \\
\hline \multicolumn{5}{|l|}{ 日 subcategory Focter } \\
\hline \multicolumn{5}{|l|}{ Gotegory Footer } \\
\hline \multicolumn{5}{|l|}{ ⿴囗ustomer Footer } \\
\hline \multicolumn{5}{|l|}{ ⿴囗十 Document Footer } \\
\hline (1) pos Fookt & & & & \\
\hline
\end{tabular}

Figure 4. Part of the report design made in a professional BI tool. Source: instructional materials of interactive documents creation.

The most often used operation in the consumption device layer was the adjustment of the report to the system delivered by the stakeholder. The main problems that had to be solved were those related to the format of imported data. The most helpful in these issues was the data conversion wizard available in the spreadsheet (MS Excel). 


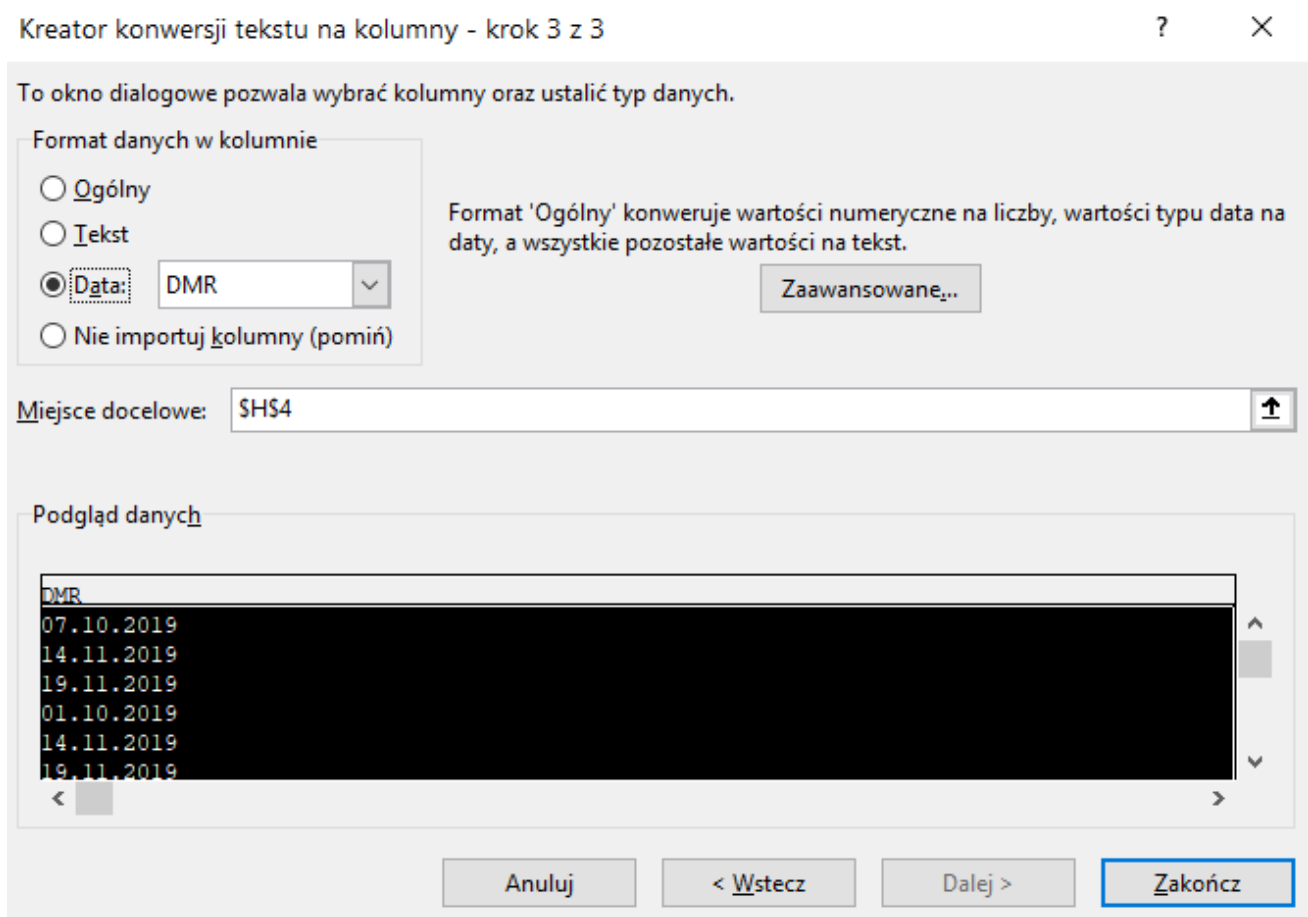

Figure 5. An example of data conversion to a suitable format. Source: own implementation.

In the business enablement layer, the investigation revealed the presence of team member mutual training. The project team consisted of people of different competences. There were people with strong competencies in the field of finance and those who had strong abilities in the field of IT tools. Mutual training allowed one to increase the percentage of automatic operations performed during report creation. The first iteration to create a report used $30 \%$ of automatic operations, and the last one $70 \%$. Thanks to this, along with the creation of subsequent reports, the number of operations involving the manual replenishment of a report decreased.

\section{Discussion and conclusion}

The conducted investigation revealed that supporting reporting in project management when there is no access to professional BI tools needs strong technical competences and great creativity in the project management team in using applications such as spreadsheets or database tools. Strong technical competences and creativity allow for the presence of all BI layers indicated by Todd (Todd, 2018). In terms of time spent on technical operations, data management processes dominate other processes in the preparation of reports. The processes related to data wrangling particularly take a lot of time. This remark is also described by Todd (Todd, 2018) in his research. Operations with data wrangling processes were related to the necessity of joining disparate data sources coming from internal financial systems 
and files containing the description of invoices, payrolls, employees and project categories. In this way, the creation of new dimensions based on text functions and assigning dimensions based on search functions turned out to be very important operations. The main tool used in the data management layer was a spreadsheet with sets of functions in point of search, conditioning and text handling. It can, therefore, be concluded, as Chung (Chung, 2019) did, that this kind of tool has high usability in terms of data management.

When it comes to intelligent calculation, the database was the most used tool. Through creation of queries, it allowed for the summing up of data for several dimensions at the same time, which wouldn't be possible if the pivot tables were applied in the spreadsheet. This operation accelerated the construction of intelligent calculation.

Operations made in the delivery mode layer were determined by the fact that the external stakeholder delivered the report template. However, additional reports did not have to be created in this way. For this reason, it was possible to use the automatic report creation available in MS Access. It was worth noticing that this way of report creation was very similar to the way of document creation in the professional BI tool. This functionality allowed accelerating the report creation and elimination of all items, as indicated by Craig (Craig, 2019), that overwhelm end-users in the perception of a report.

In terms of the consumption device layer, the most important problem was related to the adjustment of the report to the IT system delivered by the stakeholder. The options delivered by spreadsheets were very useful in these issues (i.e. data conversion wizard). Additional reports were created in the context of the awareness of human factors that influence the perception of visualisation indicated in the works of Knaflic, Few and Yau (Knaflic, 2015, 2012; Yau 2013). At this point, the most helpful options were provided by MS Access, which allowed for the separation of data from the design of their format and display.

\section{References}

1. Abbott, D. (2014). Applied predictive analytics: Principles and techniques for the professional data analyst. John Wiley \& Sons.

2. Al-Sakran, H.O. (2014). Analysis of Business Analytics Curricula and Job Demand in Saudi Arabia. Life Science Journal (11:8), pp. 918-926.

3. Bobriakov, I. (2018). Comparative Analysis of Top 6 BI and Data Visualization Tools in 2018. Retrieved from https://www.kdnuggets.com/2018/02/comparative-analysis-top-6-bidata-visualization-tools-2018.html.

4. Chiang, R.H.L., Goes, P., and Stohr, E.A. (2012). Business Intelligence and Analytics Education, and Program Development: A Unique Opportunity for the Information Systems Discipline. ACM Transactions Management Information Systems. (3:3), pp. 12. 
5. Chung, L. (2019). Microsoft Access versus Microsoft Excel for Data Analysis and Reporting. Retrieved from http://www.fmsinc.com/MicrosoftAccess/DataAnalysis/versusexcel.html, 2019.06.20.

6. Craig, W. (2019). How to Make Data Visualization Better with Gestalt Laws. Retrieved from https://www.webfx.com/blog/web-design/data-visualization-gestalt-laws/.

7. Davis, G.A., Woratschek, C.R. (2015). Evaluating Business Intelligence/Business Analytics Software for Use in the Information Systems Curriculum. Information Systems Education Journal (13:1), pp. 23-29.

8. Dykes, B. (2010). Reporting vs. Analysis: What's the Difference? Retrieved from https://theblog.adobe.com/reporting-vs-analysis-whats-the-difference/, 2010.10.19.

9. Edgington, T.M. (2011). Introducing Text Analytics as a Graduate Business School Course. Journal of Information Technology Education: Innovations in Practice 10, pp. 207-234.

10. Few, S.C. (2012). Show Me the Numbers. Analytics Press.

11. Gorman, M.F., and Klimberg, R.K. (2014). Benchmarking Academic Programs in Business Analytics. Interfaces, (44:3), pp. 329-341.

12. Green, A. (2010). Seven Free Data Wrangling Tools. Retrieved from https://www.varonis.com/blog/free-data-wrangling-tools/, 2010.10.30.

13. Knaflic, C.N. (2015). Storytelling with data. New Jersey: Willey, Hoboken.

14. Negash, S. (2004). Business intelligence. Communications of the Association for Information Systems, 13, 177-195.

15. Pomykalski, J.J. (2014). Teaching Business Intelligence through Case Studies. Proceedings of the Information Systems Educators Conference, Baltimore, Maryland, USA.

16. Presthus, W., and Bygstad, B. (2012). Business Intelligence in College: A Teaching Case with Real Life Puzzles. Journal of Information Technology Education: Innovations in Practice, 11, pp. 121-137.

17. Sircar, S. (2009). Business Intelligence in the Business Curriculum. Communications of the Association for Information Systems, 24, pp. 289-302.

18. Todd, J. (2017). Data-Driven Decisions: Business Intelligence (BI) Training Skills. All Theses And Dissertations, 127. Retrieved from http://dune.une.edu/theses/127.

19. Wilder, C.R., \& Ozgur, C.O. (2015). Business Analytics Curriculum for Undergraduate Majors. INFORMS Transactions on Education (15:2), pp. 180-187.

20. Wixom, B., Ariyachandra, T., Douglas, D., Goul, M., Gupta, B., Lyer, L., Kulkarni, U., Mooney, J.G., Phillips-Wren, G., and Turetken, O. (2014). The Current State of Business Intelligence in Academia: The Arrival of Big Data. Communications of the Association for Information Systems, 34, pp. 1-13.

21. Yau, N. (2013). Data points. Willey. 